\title{
Transcription factor EB agonists from natural products for treating human diseases with impaired autophagy-lysosome pathway
}

Jie Xu, Xiao-Qi Zhang ${ }^{*}$ and Zaijun Zhang*

\begin{abstract}
Autophagy is a highly conserved degradation process for long-lived intracellular proteins and organelles mediated by lysosomes. Deficits in the autophagy-lysosome pathway (ALP) have been linked to a variety of human diseases, including neurodegenerative diseases, lysosomal storage disorders, and cancers. Transcription factor EB (TFEB) has been identified as a major regulator of autophagy and lysosomal biogenesis. Increasing evidence has demonstrated that TFEB activation can promote the clearance of toxic protein aggregates and regulate cellular metabolism. Traditional Chinese medicine (TCM)-derived natural products as important sources for drug discovery have been widely used for the treatment of various diseases associated with ALP dysfunction. Herein, we review (1) the regulation of TFEB and ALP; (2) TFEB and ALP dysregulation in human diseases; (3) TFEB activators from natural products and their potential uses.
\end{abstract}

Keywords: TFEB, Autophagy, Autophagy-lysosome pathway, Natural products, TFEB agonists

\section{Background}

There are two major protein degradation pathways in eukaryotic cells. The ubiquitin-proteasome system (UPS) is responsible for degrading short-lived soluble proteins, while the autophagy-lysosome pathway (ALP) is mainly responsible for regulating and recycling long-lived insoluble proteins and organelles. Autophagy is a lysosomemediated bulk degradation process that occurs in all eukaryotic cells from yeasts to mammals [1]. Three main types of autophagy are currently recognized: macroautophagy, chaperone-mediated autophagy (CMA), and microautophagy. Although the mechanisms of the three subtypes are different, they have similar stimuli, such

\footnotetext{
*Correspondence: xqzhang74@hotmail.com; zaijunzhang@163.com Guangdong Provincial Engineering Research Center for Modernization of TCM, Institute of New Drug Research, Guangdong Provincial Key Laboratory of Pharmacodynamic, Constituents of TCM and New Drug Research, College of Pharmacy, Jinan University, 510632 Guangzhou, People's Republic of China
}

as environmental stress, nutrient starvation, oxidative stress, and infection [2].

In general, autophagy is divided into different stages, including initiation, elongation and maturation. Autophagy is initiated by the formation of a doublemembrane structure called a phagophore. In the initiation of autophagy, there are two important autophagy initiation complexes. One is the UN51-like Ser/Thr kinases complex (ULK) [3]. Another essential autophagy complex for autophagosome formation is the class III phosphatidylinositol 3-kinase (PI3K) complex that is also called the beclin 1 complex [4,5].

Then, two ubiquitin-like conjugation systems called the ATG12-ATG5-ATG16 complex and LC3/Atg8 are involved in the elongation of autophagy. The doublemembrane phagophore elongates to engulf various intracellular cargos, including the damaged organelles and protein aggregates, and forms an autophagosomal vesicle. LC3-II is recognized as an autophagy marker [6]. Following the formation of the complete autophagosomal structure, the autophagosome fuses with the lysosome to form 
an autolysosome. Finally, in the autolysosome, the cargos are degraded by lysosomal enzymes to maintain cellular homeostasis.

In recent years, increasing numbers of studies have shown that deficits in the ALP are strongly associated with multiple diseases. Accordingly, correcting ALP defects and enhancing the activity of the pathway are promising therapeutic strategies.

Transcription factor EB (TFEB) was identified as a master regulator of autophagy and lysosomal biogenesis. TFEB binds to a promoter motif of the coordinated lysosomal expression and regulation (CLEAR) network, which consists of genes involved in processes such as autophagy, lysosomal biogenesis and membrane repair, and positively coordinates related downstream target genes [7]. It has been widely demonstrated that TFEB activators can ameliorate diseases related to ALP dysfunction, including neurodegenerative diseases, lysosomal storage disorders and so on $[8,9]$.

Owing to having fewer side effects and multitargeted mechanisms of action, traditional Chinese medicine (TCM)-derived natural products as important sources for drug discovery have great potential in the treatment of various ALP dysfunction-related diseases. In this review, we present an overview of the regulation of TFEB and ALP, the application of TFEB in ALP dysfunctionassociated diseases, and TFEB activators derived from natural products. Furthermore, we look forward to identifying ideal TFEB activators with considerably higher specificity for the treatment of human diseases.

\section{The regulation of TFEB and ALP \\ The $m T O R$ regulatory pathways}

Mammalian (or Mechanistic) target of rapamycin (mTOR), a serine/threonine kinase, is the best-studied regulator of mammalian autophagy. Based on their structural differences, mTOR complexes are classified as mTOR complex (mTORC) 1 and mTORC2. mTORC1 is composed of mTOR, regulatory associated protein of mTOR (Raptor), G protein $\beta$-subunit-like protein (GßL), proline-rich Akt substrate of $40 \mathrm{kDa}$ (PRAS40), and DEP domain-containing mTOR-interacting protein (DEPTOR) [2], and it responds to multiple stresses, including nutrients, growth factors and cellular energy status [10].

Under nutrient-rich conditions, PRAS40 is phosphorylated by Akt and dissociates from Raptor to activate mTORC1. Activated mTORC1 phosphorylates ULK1 at Ser757 to inhibit the ULK1 activity involved in autophagosome formation. However, AMP-activated protein kinase (AMPK) phosphorylates ULK1 at the Ser317 and Ser777 sites to promote ULK1 activity and autophagy. Although mTORC1 is the major sensor of nutrition and growth factor signals, autophagy can also be regulated by mTORC2 through the mTORC2-AktFoxO3 signaling pathway [11].

mTORC2 is composed of mTOR, rapamycin-insensitive companion of mTOR (Rictor), GßL, stress-activated protein kinase-interacting protein (SIN) 1, and protein observed with Rictor (PROTOR) [2]. mTORC2 can participate in autophagy regulation through the FOXO3 pathway. FoxO3 is a transcription factor that is activated under starvation conditions and promotes the transcription of genes that regulate autophagy induction [12]. mTORC2 phosphorylates Akt at Ser473, followed by Akt phosphorylation of FOXO3. Phosphorylated FOXO3 binds to the 14-3-3 protein, which retains it in the cytoplasm, preventing activation of autophagy gene transcription.

\section{The regulation of TFEB}

TFEB is a basic helix-loop-helix leucine zipper transcription factor, a member of the MiT family, that regulates metabolism and cellular clearance as a master regulator of the ALP (Fig. 1) [13]. mTORC1 and extracellular signal-regulated kinase 2 (ERK2, also known as MAPK1) are the two main kinases known to phosphorylate TFEB under nutrient-rich conditions in most cell types [14]. Under normal conditions, such as nutrient availability and no lysosomal stress, mTORC1 phosphorylates TFEB at the Ser142 and Ser211 sites. Phosphorylated TFEB binds to 14-3-3 protein, which sequesters it in the cytoplasm. However, under conditions of starvation or lysosomal stress, mTORC1 is released from the lysosomal membrane and becomes inactive, and no longer phosphorylates TFEB. The unphosphorylated TFEB translocates into the nucleus, where it promotes the transcription of its target genes $[15,16]$. TEEB is identified to bind to the CLEAR sequence, leading to upregulation of the autophagy and lysosomal genes. The expression of autophagic and lysosomal target genes, such as Tfeb, Atg9b, and Sqstm 1, etc., can be positively regulated by TFEB [15].

The TFEB promoter contains multiple CLEAR sequences, and thus TFEB upregulates its own expression in an autoregulatory loop. Both the fed-state sensing nuclear receptor farnesoid $\mathrm{X}$ receptor (FXR) and the fasting transcriptional activator cAMP response element-binding protein (CREB) regulate the expression of TFEB. CREB up-regulate TFEB expression by recruiting the coactivator CRTC2. However, FXR transrepress autophagy genes by disrupting the functional CREB-CRTC2 complex [17]. In addition, many factors regulate TFEB activity. The peroxisome proliferatoractivated receptor- $\gamma$ coactivator $1 \alpha$ (PGC- $1 \alpha$, also known as PPARGC1A) has been identified as a direct TFEB target [18]. The activation of nuclear receptor peroxisome 


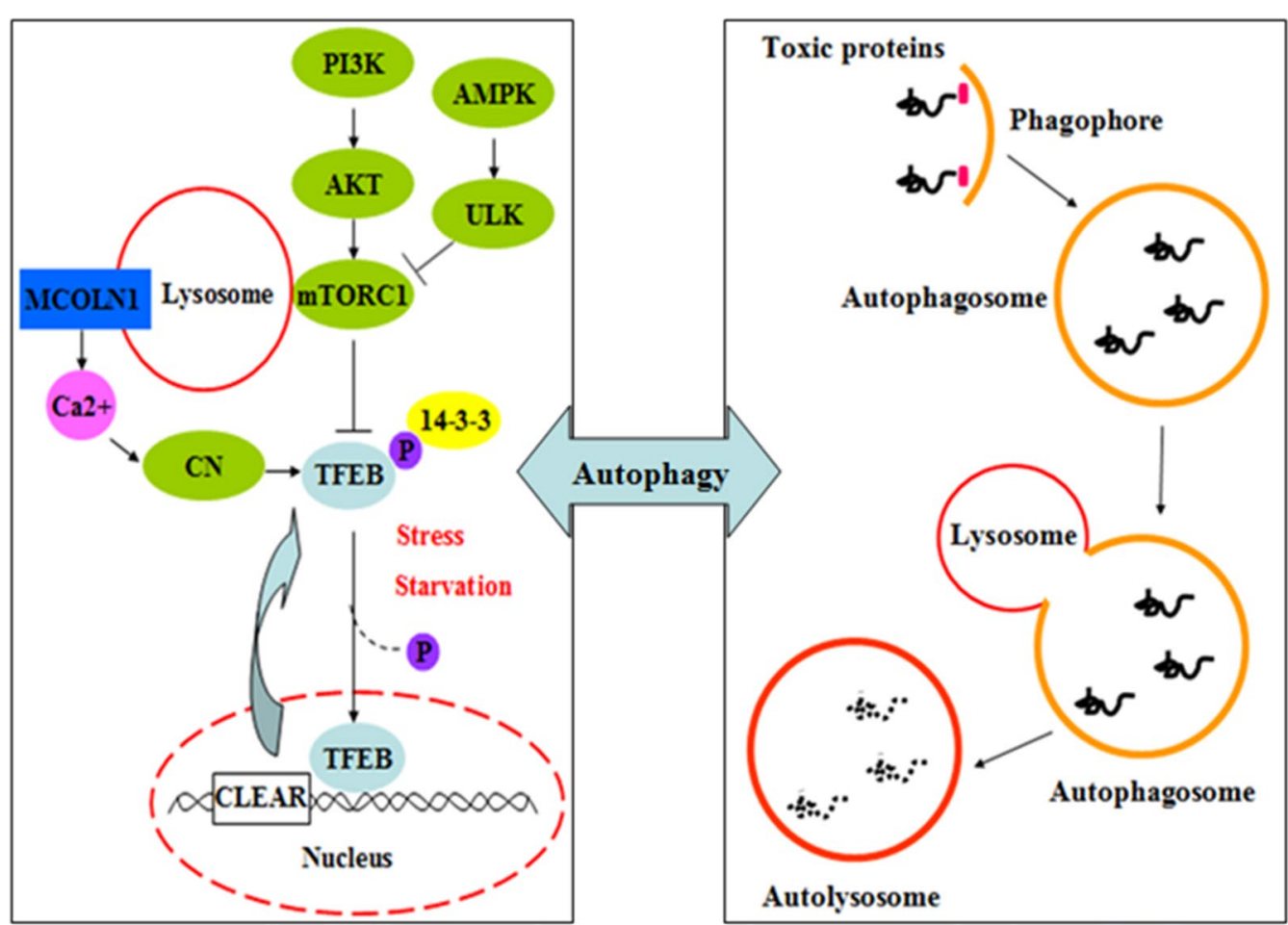

Fig. 1 The regulation of TFEB and ALP. MTORC1 holds TFEB in a phosphorylated state. Phosphorylated TFEB binds to the 14-3-3 protein, which sequesters it in the cytoplasm. However, mTORC1 dependent/independent pathways that activate TFEB can dephosphorylate TFEB, and dephosphorylated TFEB translocates to the nucleus and binds to the CLEAR sequence, leading to upregulation of the autophagy and lysosomal genes. PI3K class III phosphatidylinositol 3-kinase, AMPK AMP-activated protein kinase, ULK UN51-like Ser/Thr kinases complex, mTOR Mammalian (or Mechanistic) target of rapamycin, mTORC mTOR complex, CLEAR coordinated lysosomal expression and regulation, TFEB transcription factor EB, MCOLN1 calcium channel mucolipin 1, CN calcineurin

proliferator-activated receptor $\alpha$ (PPAR $\alpha)$ leads to nuclear translocation of TFEB and induces TFEB expression [19]. At the same time, PPAR $\alpha$, retinoid X receptor $\alpha(\mathrm{RXR} \alpha)$, and PGC- $1 \alpha$ form a transcriptionally active complex. And the activation of PPAR $\alpha$ can induce the recruitment of the PPAR $\alpha-\mathrm{RXR} \alpha-\mathrm{PGC}-1 \alpha$ complex on the TFEB promoter, thus regulating lysosomal biogenesis [20].

TFEB is regulated by another positive feedback loop. The calcium channel mucolipin 1 (MCOLN1), a transcriptional target of TFEB, creates a microdomain of high $\mathrm{Ca}^{2+}$ concentration near the lysosomal membrane upon nutrient deprivation [21]. The higher $\mathrm{Ca}^{2+}$ concentration leads to the activation of phosphatase calcineurin, which dephosphorylates TFEB, promoting TFEB nuclear translocation and the transcription of target genes [21]. Knockdown of the Rag GTPases, a part of the lysosomal nutrient-sensing machinery that signals to mTORC1, induces the nuclear translocation of TFEB even in nutrient-rich conditions [22]. The mutation of serine to alanine on TFEB abolishes its phosphorylation, and it then shows a significantly increased nuclear localization $[16$,
23]. More recently, endoplasmic reticulum stress has been identified to induce the nuclear translocation of TFEB as part of the integrated stress response. In this case, TFEB is activated by an RNA-like endoplasmic reticulum kinase (PERK/EIF2AK3)-dependent mechanism that promotes activation of calcineurin and nuclear translocation of TFEB [24].

\section{ALP and TFEB dysregulation-associated human diseases Lysosomal storage disorders (LSDs)}

LSDs are caused by the accumulation of undegraded materials in the lysosomal lumen due to a genetic deficiency in specific lysosomal proteins. The clinical outcome of undigested matrix storage in multiple organs and systems leads to variable neurological, visceral and skeletal manifestations [25].

Pompe disease as a severe metabolic myopathy is caused by acid alpha-glucosidase (GAA) deficiency, which is an enzyme responsible for breaking down glycogen to glucose, leading to an accumulation of glycogen. Pompe disease is characterized by both lysosomal abnormalities and autophagic dysfunction. Overexpression of 
TFEB in cell systems and a mouse model of this disease decreases glycogen accumulation and lysosomal size, improves autophagosome processing, and relieves the excessive load of autophagic vacuoles [26].

It has been reported that TFEB activation enhances the folding, trafficking and lysosomal activity of destabilized glucocerebrosidase (GC) mutants, which are associated with the development of Gaucher disease. Moreover, TFEB activation also rescues the activity of the $\beta$-hexosaminidase mutant involved in the development of another LSDs, Tay-Sachs disease [27]. Multiple sulfatase deficiency (MSD), a severe type of LSDs, is caused by defective posttranslational activation of sulfatasemodifying factor 1 and simultaneous deficiency of all sulfatases, leading to accumulation of glysosaminoglycans (GAGs) and aberrant autophagy.

Another LSD, known as mucopolysaccharidosis (MPS) type IIIA, which is caused by heparan sulfamidase deficiency, results in the progressive accumulation of GAGs and cellular vacuolization. TFEB overexpression in glia-differentiated neuronal stem cells (NSCs) derived from mouse models of MSD and MPS-IIIA significantly reduces the level of intracellular GAGs, decreases cellular vacuolization, and restores normal cell morphology. Notably, TFEB overexpression rescues not only the GAGs accumulation but also secondary pathological processes associated with LSDs such as inflammation and cell death seen in vivo in MSD [28].

Overexpression of TFEB reduces the accumulation of lipofuscin in cell models derived from mice and patients with Batten disease, which is caused by mutations of the CLN3 gene [28]. Cystinosis is an autosomal recessive LSDs characterized by the accumulation of cystine into lysosomes. Cystinosis is caused by mutations in the CTNS gene, which encodes the cystine lysosomal transporter, cystinosin. The deficiency or dysfunction of cystinosin causes the accumulation of cystine in lysosomes throughout the body. Lack of cystinosin decreases the TFEB level and induces TFEB nuclear translocation. Both genetic and chemical activation of TFEB are able to reduce cystine stores, stimulate delayed cargo processing, and rescue the aberrant lysosomal compartment morphology in cystinotic cells [29].

The mechanism of TFEB-mediated intracellular clearance not only includes the enhancement of lysosomal activity and biogenesis but also TFEB-induced lysosomal exocytosis. TFEB-induced lysosomal exocytosis requires lysosomal recruitment to the cell surface in a $\mathrm{Ca}^{2+}$-independent manner first and TFEB enhances $\mathrm{Ca}^{2+}$-mediated fusion of lysosomes with the plasma membrane via activation of the lysosomal $\mathrm{Ca}^{2+}$ channel MCOLN1 [28]. In summary, TFEB-mediated proteostasis regulation generally rescues destabilized mutations in
LSDs, and this suggests that TFEB may be an appealing target to rescue enzyme homeostasis in LSDs.

\section{Neurodegenerative diseases}

Neurodegenerative diseases, which are age-dependent diseases caused by the loss of neurons and spinal marrows, leading to functional disorders of the brain, are characterized by intracellular accumulation of aggregateprone proteins and damaged protein degradation systems. As is widely acknowledged, the ALP pathway in neurodegenerative diseases plays an essential role in the clearance of intracellular misfolded protein aggregates to maintain homeostasis.

Huntington's disease (HD) is caused by trinucleotide CAG repeat expansions in the first exon of the huntingtin (HTT) gene. The CAG repeat is translated into an expanded polyglutamine (polyQ) tract in the amino terminal region of the HTT protein, resulting in misfolding into a pathogenic conformation. Recently, overexpression of TFEB was found to reduce intracellular HTT protein aggregation in a mouse model of HD. In addition, TFEB has been identified as a downstream transcriptional target of PGC- $1 \alpha$, which has been shown to ameliorate the symptoms of HD mice through activation of TFEB [30].

Parkinson's disease (PD) is a progressive neurodegenerative disease affecting dopaminergic neurons in the substantia nigra. PD is pathologically characterized by the accumulation of proteinaceous cytoplasmic inclusions termed Lewy bodies, containing misfolded and aggregated $\alpha$-synuclein [31]. Furthermore, PD is accompanied by lysosomal deficiency. Overexpressing TFEB or inducing its nuclear translocation eliminates this deficit and attenuates $\alpha$-synuclein pathology $[8,32]$. Another pathological hallmark of PD is the accumulation of damaged mitochondria due to mitophagy dysfunction. It has been reported that the PINK1-Parkin pathway plays an essential role in regulating the selective elimination of damaged mitochondria via mitophagy. TFEB translocates to the nucleus and displays transcriptional activity in a PINK1-Parkin-dependent manner [33]. In addition, Parkin, through its effects on PARIS, plays a crucial role in overall mitochondrial homeostasis via cellular regulation of the PGC-1 $\alpha$-TFEB signaling pathway [34].

Alzheimer's disease (AD) is the most common form of neurodegenerative disease in the aged. Extracellular amyloid plaques consisting of $\beta$-amyloid peptides $(A \beta)$ and intracellular neurofibrillary tangles (NFTs) composed of hyperphosphorylated tau protein are considered the main pathological characteristics of $\mathrm{AD}$. AD is correlated with genetic origins, such as mutations in amyloid precursor protein (APP) and presenilin (PS) 1 and 2. [35]. The impaired clearance of these aggregation-prone proteins results in neurotoxicity, neurodegeneration, and 
memory deficits. In addition to the UPS and CMA pathways, the selective autophagic clearance of aggresomes, termed aggrephagy, is activated. Accumulating evidence has demonstrated that TFEB can attenuate protein aggregates in cell and mouse models of $\mathrm{AD}$ and other tauopathies, resulting in alleviation of neurodegeneration and improvement of behavioral deficits, as well as the recovery of cognitive impairment $[9,36]$.

Spinal and bulbar muscular atrophy (SBMA), known as Kennedy disease, is a motor neuron disease. It is caused by CAG repeat expansion in the first exon of the androgen receptor (AR) gene. According to several studies, autophagy is involved in the pathogenesis of SBMA. The expression of TFEB can activate autophagy, reduce aggregation of the abnormal AR protein, and alleviate the motor phenotypes [37].

Amyotrophic lateral sclerosis (ALS) is characterized by the formation of protein inclusions and the degeneration of motor neurons. ALS pathogenesis is associated with several mutations. Notably, the transactive response (TAR) DNA-binding protein $43 \mathrm{kDa}$ (TDP-43) aggregate has been identified as the major component of protein inclusions in ALS. The activation of TFEB enhances autophagy and the clearance of TDP-43 aggregates [38].

In conclusion, promoting the function of ALP by activating TFEB may be a therapeutic strategy for neurodegenerative disorders.

\section{Cancers}

Cancer is characterized by a genetic and metabolic imbalance causing abnormal cell growth. Autophagy, serving as a double-edged sword due to its complex effects on cancer, displays both pro-tumorigenic and anti-tumorigenic effects [39, 40].

Autophagy is a catabolic process used to degrade longlived proteins and cytoplasmic components, and then it supports tumor progression through reusing the produced metabolites to synthesize new macromolecules or using them as an energy supply. Glycogen synthase kinase-3 (GSK3) inhibition triggers pro-survival signals by increasing the activity of the autophagic/lysosomal network. TFEB overactivation increases the proliferation of pancreatic cancer cells [41]. Chromosomal translocations involving TFEB and TFE3 are found in renal cell carcinoma [42]. TMEM106B modulates the expression of the CLEAR network lysosomal genes in lung cancer cells in a TFEB-dependent manner, and drives lung cancer metastasis [43]. Moreover, autophagy can also protect against tumors by depriving them of nutrients and restricting cell proliferation. Hence, the role of autophagy in tumorigenesis is controversial because of the crosstalk between autophagy and apoptosis.

\section{Other diseases}

It has been documented that TFEB can control lipid catabolism by regulating $\mathrm{PGC}-1 \alpha$, a key regulator of lipid metabolism. TFEB overexpression in the liver prevents weight gain and associated metabolic syndrome in both diet-induced and genetic mouse models of obesity [44]. TFEB, as a PGC- $1 \alpha$-dependent regulator of adipocyte browning, has therapeutic potential in metabolic dysfunction. Adipocyte-specific TFEB overexpression in mice is protective against diet-induced obesity, insulin resistance, and metabolic sequelae [18].

Age-associated cardiovascular diseases are characterized by increased oxidative stress associated with autophagy dysfunction. Reactive oxygen species (ROS) can not only impair ventricular function but also block autophagy $[45,46]$. Monoamine oxidase (MAO) is a potent ROS source in several cardiomyopathies. MAO-A can degrade catecholamine and serotonin to produce hydrogen peroxide $\left(\mathrm{H}_{2} \mathrm{O}_{2}\right)$, which results in oxidative stress. TFEB overexpression attenuates the negative impacts of the MAO- $\mathrm{A} / \mathrm{H}_{2} \mathrm{O}_{2}$ axis by reducing autophagosome accumulation and cardiomyocyte death [47]. Furthermore, the nuclear translocation and activation of TFEB can induce autophagy and confer cardioprotection in cardiomyocytes with overexpression of MAO-A [48]. Atherosclerosis is the most serious threat to human cardiovascular health. Endothelial oxidative injury is a driving force in the pathogenesis of atherosclerosis. In human umbilical vein endothelial cells (HUVECs), endothelial oxidative injury stimulated by palmitic acid is counteracted by inducing autophagy in a TFEB-dependent manner [49].

TFEB gene transfer is available for the treatment of liver disease caused by alpha-1-anti-trypsin deficiency [50]. Recent evidence has suggested that TFEB has a broad effect on modulating inflammatory reactions, immune responses [51,52] and bone resorption [53].

\section{TFEB activators from natural products}

TFEB, a master regulator of autophagy and lysosomal biogenesis, has become an attractive target for alleviating ALP dysfunction. Owing to their lesser side effects and multitargeted action, TCM-derived natural products have therapeutic promise for multiple diseases. Some active ingredients from TCM have been reported to activate TFEB via multiple mechanisms, including mTOR inhibition, Akt inhibition, and $\mathrm{Ca}^{2+}$-dependence, as well as direct TFEB activation and so on (Fig. 2). Additionally, these active ingredients can regulate autophagic and lysosomal function, enhance the clearance of toxic aggregates, engage in apoptosis by activating TFEB (Table 1 ). 


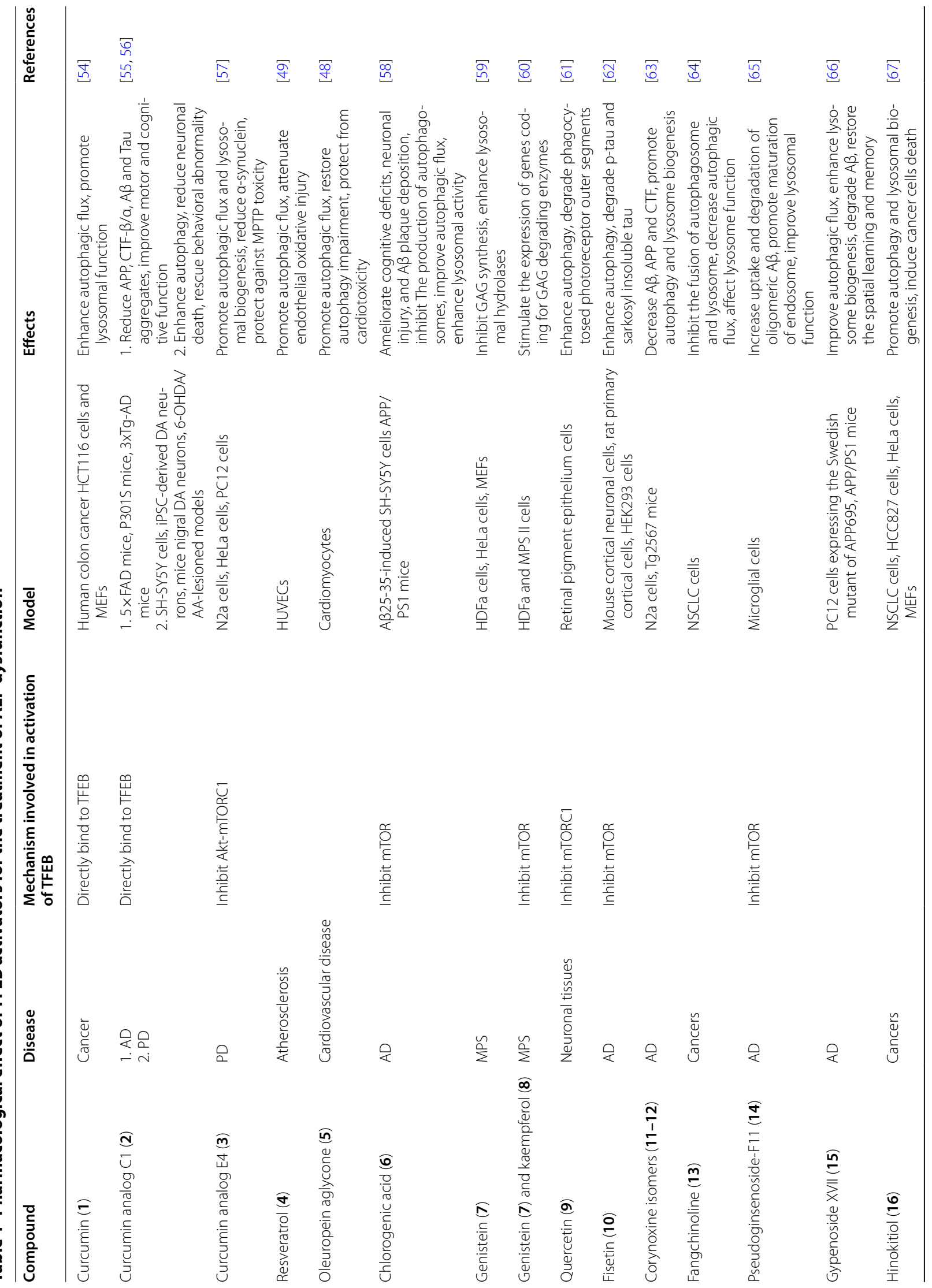




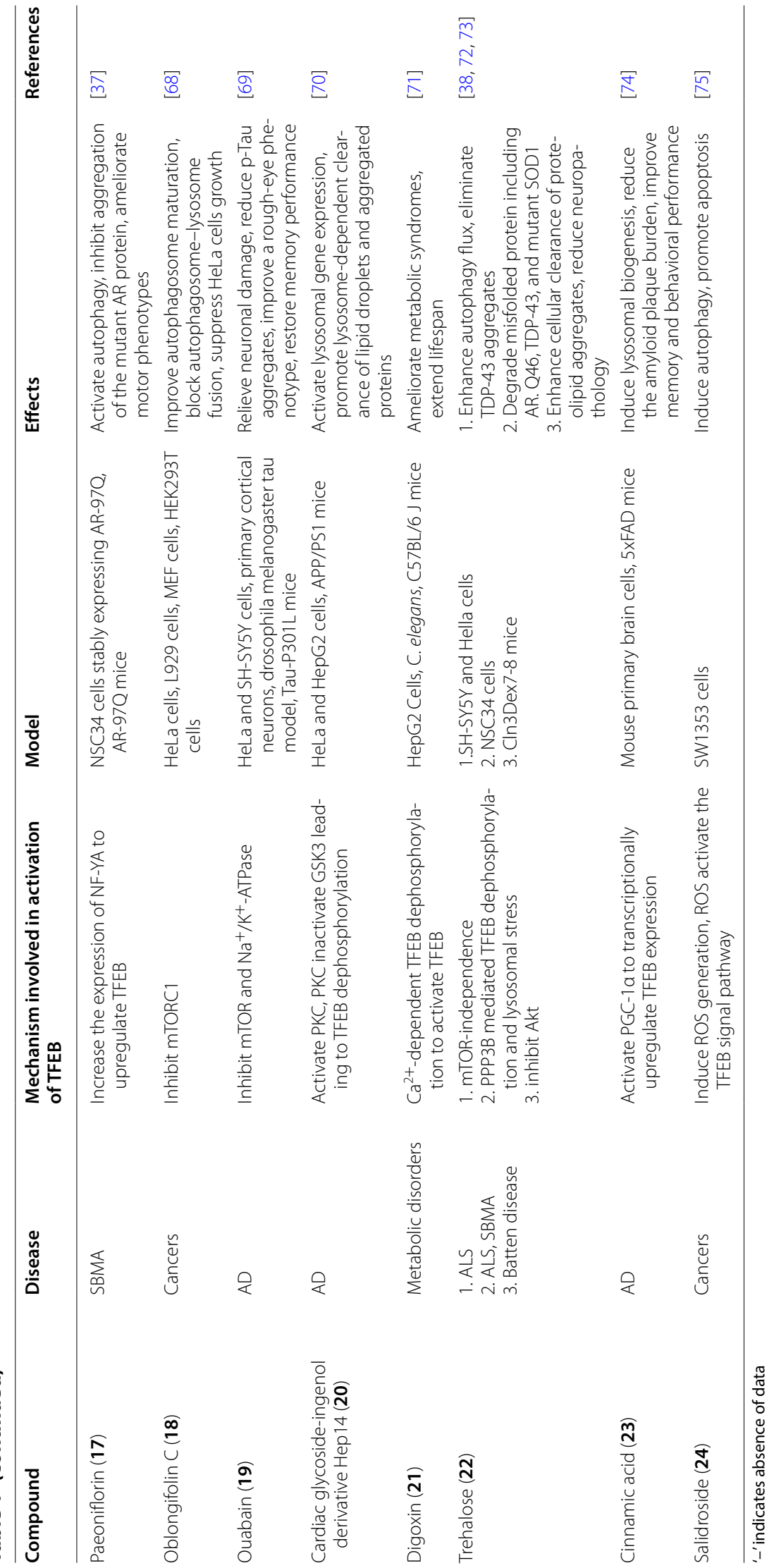




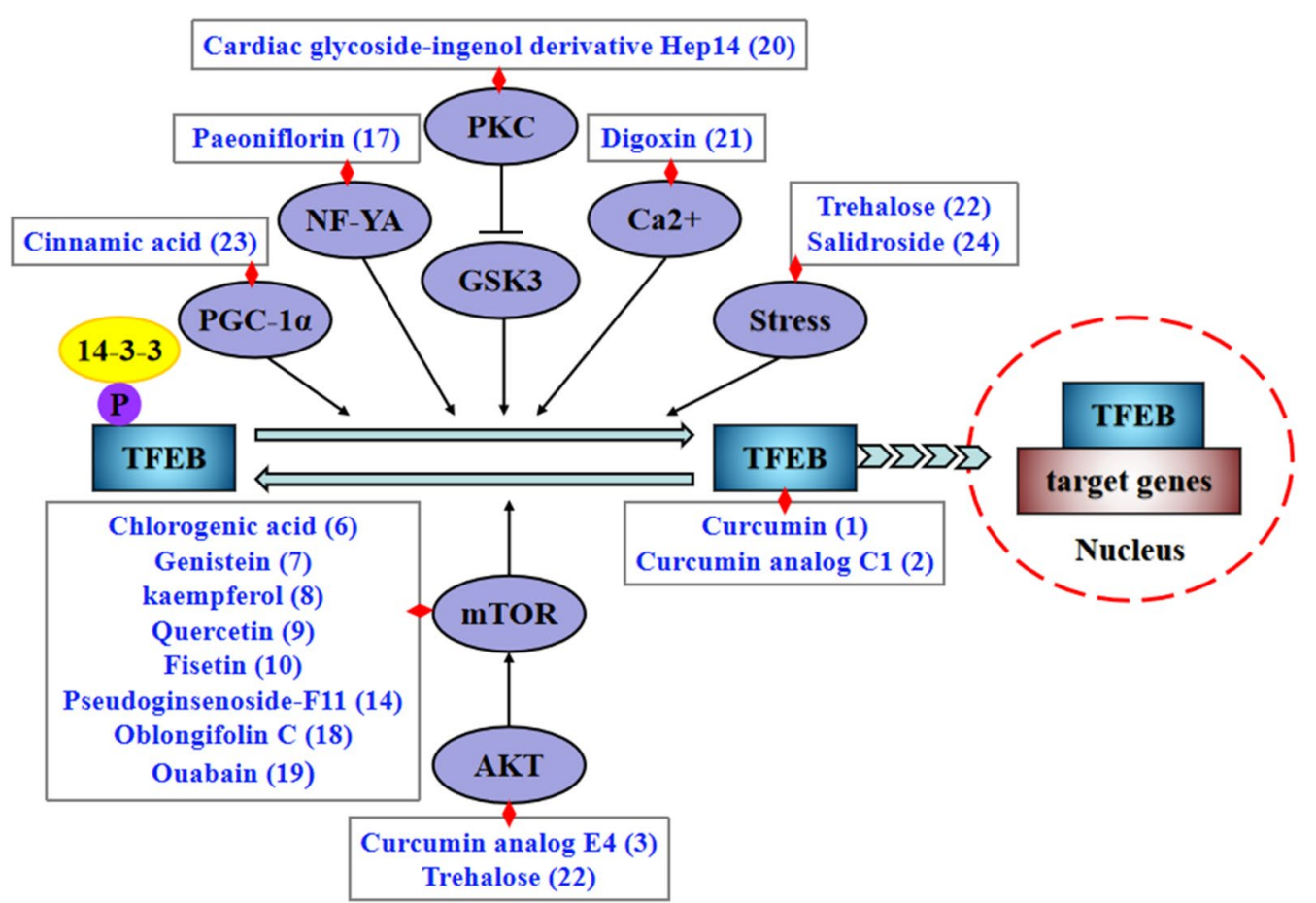

Fig. 2 The TFEB activators from natural products. Phosphorylated TFEB binds to the 14-3-3 protein, which sequesters it in the cytoplasm. Some active ingredients of TCM can dephosphorylate TFEB and translocate TFEB to the nucleus via multiple mechanisms. PKC protein kinase C, TFEB transcription factor EB, mTOR Mammalian (or Mechanistic) target of rapamycin, PGC-1a peroxisome proliferator-activated receptor- $\gamma$ coactivator 1a, NF-YA nuclear factor-YA

\section{Polyphenols}

\section{Curcumin and its analogs}

Curcumin (1, Fig. 2) is a hydrophobic polyphenol isolated from Curcuma longa L., exhibiting diverse pharmacologic effects [76-78]. It has been extensively demonstrated that curcumin induces autophagy by suppressing the PI3K-Akt-mTOR signaling pathway or directly activating TFEB. It has been documented that curcumin directly binds to TFEB, promotes TFEB nuclear translocation, reduces the phosphorylation level of TFEB, and increases the transcriptional activity of TFEB. Moreover, curcumin enhances autophagic flux in human colon cancer HCT116 cells and mouse embryonic fibroblasts (MEFs), and promotes lysosomal function via suppression of mTOR. Curcumin-induced lysosomal activation promotes cell survival, and lysosome inhibition is able to cause more cell death in curcumin-treated HCT116 cells, which may facilitate the development of curcumin as an anticancer agent [54].

However, due to the poor absorption and low bioavailability of curcumin, several derivatives of curcumin have been chemically synthesized to improve its bioavailability and potency. A synthesized curcumin monocarbonyl derivative termed $\mathrm{C} 1$ (2, Fig. 2) has been identified as a potent mTOR-independent activator of
TFEB. Compound C1 directly binds to TFEB at the $\mathrm{N}$ terminus and promotes TFEB entry into the nucleus, without affecting TFEB phosphorylation or inhibiting the activities of mTOR and MAPK1/ERK2-MAPK3/ERK1. $\mathrm{C} 1$ is effective in enhancing autophagy and lysosome biogenesis in vitro and in vivo [79]. $\mathrm{C} 1$, an mTOR-independent activator of TFEB, efficiently reduces APP, APP $\mathrm{C}$-terminal fragments (CTF- $\beta / \alpha), \mathrm{A} \beta$ and Tau aggregates in three $\mathrm{AD}$ animal models, such as beta-amyloid precursor protein pathology (5xFAD mice), tauopathy (P301S mice) and the APP/Tau combined pathology (3xTg-AD mice). At the same time, $\mathrm{C} 1$ improves the motor and cognitive function of mice models [55]. C1 enhances TFEB nuclear translocation and autophagy in 6-hydroxydopamine/ascorbic acid (6-OHDA/AA)-lesioned models of PD to exert neuroprotective effects. $\mathrm{C} 1$ significantly reduces neuronal death in SH-SY5Y cells, iPSC-derived DA neurons and mice nigral DA neurons, and rescues the behavioral abnormalities of 6-OHDA/AA treated mice [56]. Furthermore, $\mathrm{C} 1$ promotes the transport of Hex and Gal from lysosomes to the plasma membrane via mTORC1-independent TFEB activation [80]. Curcumin monocarbonyl analog E4 (3, Fig. 2) induces TFEB activation through Akt-mTORC1 inhibition. E4 promotes autophagy flux and lysosomal biogenesis, reduces 
$\alpha$-synuclein levels and protects against 1-methyl-4-phenyl-1,2,3,6-tetrahydropyridine (MPTP) toxicity in vitro [57].

\section{Resveratrol}

Resveratrol (4, Fig. 2) is a natural polyphenol that is mainly isolated from grapes. Resveratrol is associated with multiple health benefits, such as neuroprotective and anti-atherosclerosis effects. Resveratrol activates TFEB in HUVECs, and ameliorates endothelial oxidative injury by inducing autophagy [49]. In addition, TFEB can be acetylated, inhibiting gene transcription, while SIRT1 can deacetylate TFEB and improve the transcription of its target genes [81]. Resveratrol, as a SIRT1 activator, can promote the nuclear translocation of TFEB and upregulate the target gene levels of TFEB [82].

\section{Oleuropein aglycone}

Oleuropein aglycone (5, Fig. 2), the main polyphenol found in olive oil, has been proven to activate autophagy against neurodegeneration $[83,84]$.
Oleuropein aglycone can translocate TFEB to the nucleus and upregulate TFEB target genes. Oleuropein aglycone regulates autophagic flux in cardiomyocytes and restores autophagy impairment resulting from MAO-A induced oxidative stress, protecting against cardiotoxicity [48].

\section{Chlorogenic acid}

Chlorogenic acid (6, Fig. 3) is a phenolic acid compound extracted from honeysuckle, tea and coffee [85, 86]. Chlorogenic acid promotes TFEB nuclear translocation and increases TFEB protein levels by the mTORTFEB signaling pathway. Chlorogenic acid can inhibit the production of autophagosomes, improve the fusion of autophagosomes with lysosomes, and enhance lysosomal function in vitro and in vivo. Moreover, chlorogenic acid effectively ameliorates cognitive deficits, neuronal injury, and $A \beta$ plaque deposition in APP/PS1 mice [58].<smiles>COc1cc(/C=C/C(=O)CC(=O)/C=C/c2ccc(O)c(OC)c2)ccc1O</smiles><smiles>Oc1ccc(/C=C/c2cc(O)cc(O)c2)cc1</smiles>

Curcumin (1)<smiles>COc1ccccc1/C=C/C(=O)/C=C/c1ccccc1OC</smiles><smiles>[R]C(=O)OCC1=CO[C@@H](O)/C(=C/C)[C@H]1C(C)C(=C)OCCc1ccc(O)c(O)c1</smiles>

Curcumin analog $\mathrm{C} 1(2)$<smiles>Cc1ccccc1/C=C/C(=O)/C=C/c1ccccc1I</smiles>

Oleuropein aglycone (5)<smiles>[TlH]</smiles><smiles>O=C(/C=C/c1ccc(O)c(O)c1)O[C@@H]1C[C@](O)(C(O)=S)C[C@H](O)[C@H]1O</smiles>

Curcumin analog E4 (3)

Chlorogenic acid (6)

Fig. 3 Chemical structures of polyphenols, including curcumin, curcumin analog C1, curcumin analog E4, resveratrol, oleuropein aglycone and chlorogenic acid 


\section{Flavonoids}

\section{Genistein and kaempferol}

Genistein and kaempferol (7-8, Fig. 4) are natural flavonoids. Genistein is able to activate TFEB and increase mRNA levels of representative CLEAR network genes, such as SQSTM1, CTSD, SMPD1, and reduce intracellular cystine levels in cystinotic cells [29]. In addition, genistein promotes the nuclear translocation and target gene levels of TFEB. Genistein not only inhibits the expression of genes involving in GAG synthesis but also enhances the expression of genes coding for various lysosomal hydrolases [59]. It has been observed that genistein, kaempferol and a mixture of them can increase TFEB expression and decrease the levels of mTOR transcripts in both HDFa and MPS II cells, which may stimulate the expression of genes coding for GAG degrading enzymes [60]. Therefore, it offers therapeutic strategies for the treatment of some LSDs.

\section{Quercetin}

Quercetin (9, Fig. 4) is a plant-derived flavonoid compound. Quercetin treatment activates TFEB by inhibiting mTORC1 in the retinal pigment epithelium cells. Activated TFEB facilitates the degradation of phagocytosed photoreceptor outer segments [61]. However, the concentration of quercetin to effectively activate TFEB is relatively higher than the reported blood concentration seen in human clinical experiments. Therefore, studies of its pharmacokinetic and pharmacodynamic properties are necessary; And pharmaceutical preparation approaches to improve the bioavailability of quercetin is needed.

\section{Fisetin}

Fisetin (10, Fig. 4) is a flavonol from Rhus succedanea L. Fisetin has been recently reported to activate TFEB via mTOR inhibition and stimulate autophagic degradation of phosphorylated tau in neurons [62].

\section{Alkaloids}

\section{Corynoxine isomers}

Corynoxine (11-12, Fig. 5) is isolated from Uncaria rhynchophylla (Miq.) Miq.ex Havil. and induces the nuclear translocation of TFEB. Corynoxine and corynoxine $B$ decrease $A \beta$ through increasing the degradation of APP and CTF, promoting autophagy and lysosome biogenesis [63].

\section{Fangchinoline}

Fangchinoline (13, Fig. 5) is an alkaloid isolated from Stephania tetrandra S. Moore. Fangchinoline can promote the nuclear translocation of TFEB and

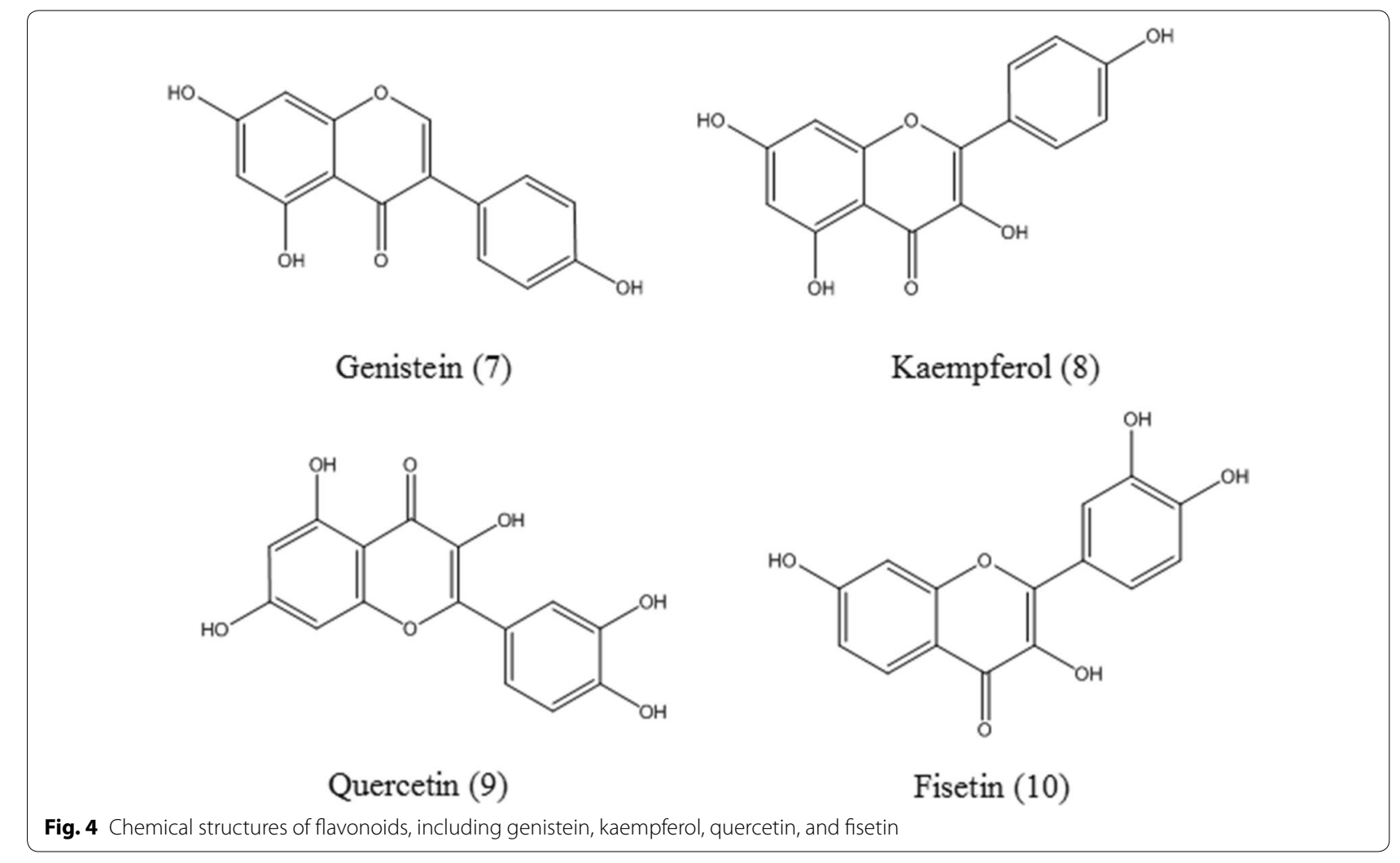




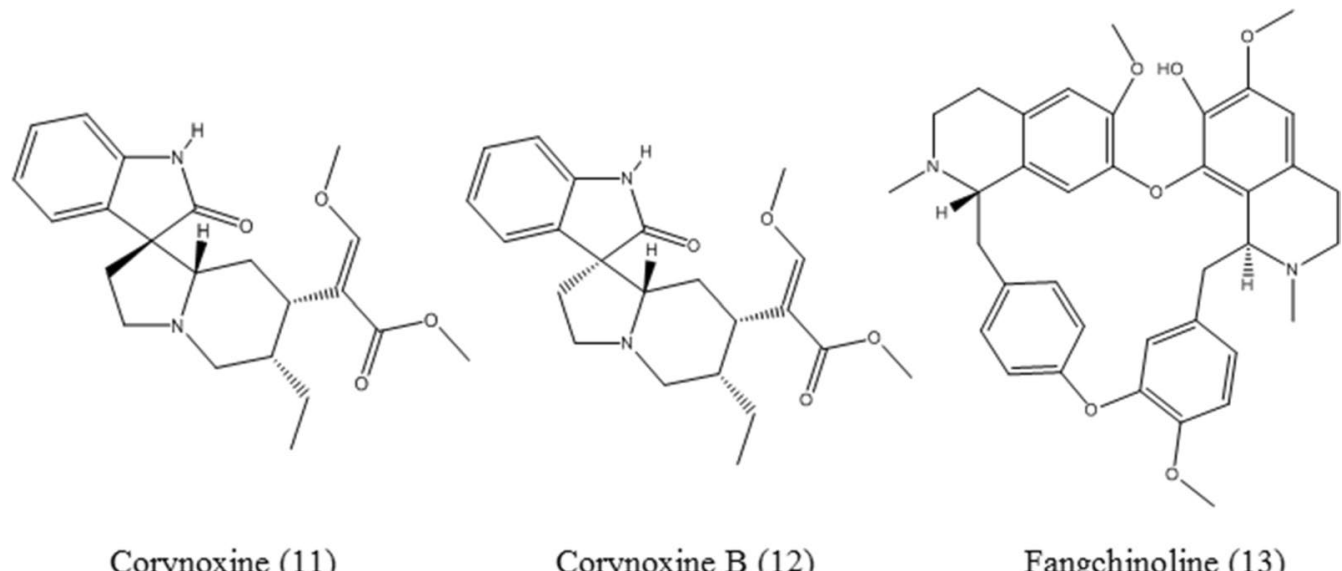

Fig. 5 Chemical structures of alkaloids, including corynoxine, corynoxine B and fangchinoline

the expression of its target genes at an early stage of autophagy in non-small cell lung cancer (NSCLC) cells. However, in the late period of treatment, fangchinoline inhibits the fusion of the autophagosome and lysosome, and affects lysosomal function, leading to a decrease in the autophagic flux [64]. Accordingly, whether a compound induces or inhibits autophagy is a complex problem, and it depends on the treatment time. It is necessary to screen autophagy inducers or inhibitors by using a real-time monitored method.

\section{Terpenoids}

\section{Pseudoginsenoside-F11}

Pseudoginsenoside-F11 (14,Figure 6), an ocotillol-type saponin that is derived from leaves of Panax pseudoginseng subsp. himalaicus HARA (Himalayan Panax), has beneficial effects in vitro and in vivo on central nervous system disorders, such as PD and AD [87, 88]. Pseudoginsenoside-F11 facilitates the nuclear translocation of TFEB through mTOR inhibition. Pseudoginsenoside-F11 has been proven to increase the uptake and degradation of oligomeric $A \beta$ in microglia, most likely by promoting the maturation of endosomes and improving the function of the lysosome [65].

\section{Gypenoside XVII}

Gypenoside XVII (15, Fig. 6), a major saponin abundant in ginseng and Panax notoginseng, has been shown to rescue autophagy flux and enhance lysosome biogenesis through TFEB activation. Gypenoside XVII facilitates the autophagic removal of $A \beta$ in cellular and rodent models of AD. Meanwhile, gypenoside XVII restores the spatial learning and memory of APP/PS1 mice [66].

\section{Hinokitiol}

Hinokitiol ( $\beta$-thujaplicin) (16, Fig. 6), a monoterpenoid compound extracted from the wood of cupressaceous, exhibits multiple bioactivities such as anti-inflammatory, anti-bacterial and anticancer activities through apoptosis and autophagy. Hinokitiol activates the TFEB nuclear translocation for autophagy and lysosomal biogenesis, and induces cancer cell death [67].

\section{Paeoniflorin}

Paeoniflorin (17, Fig. 6), which is the major bioactive substance of Moutan cortex and Paeonia lactiflora Pall., has been reported to have various functions, including antioxidation, anti-inflammation and neuroprotection [89]. Paeoniflorin upregulates TFEB in a nuclear factor-YA (NF-YA)-dependent manner to activate autophagy, inhibit aggregation of mutant AR and to ameliorate motor phenotypes in SBMA cells and transgenic animal models [37].

\section{Oblongifolin C}

Oblongifolin C (18, Fig. 6) is a natural compound from the Garcinia yunnanensis Hu. Oblongifolin C can induce TFEB dephosphorylation and subsequent nuclear translocation by inhibiting mTORC1. Oblongifolin $\mathrm{C}$ improves autophagosome maturation but blocks autophagosome-lysosome fusion by engaging the SNARE protein syntaxin 17 (STX17). In addition, the combination of oblongifolin $\mathrm{C}$ and hydroxycitrate can further suppress HeLa cells growth [68]. 


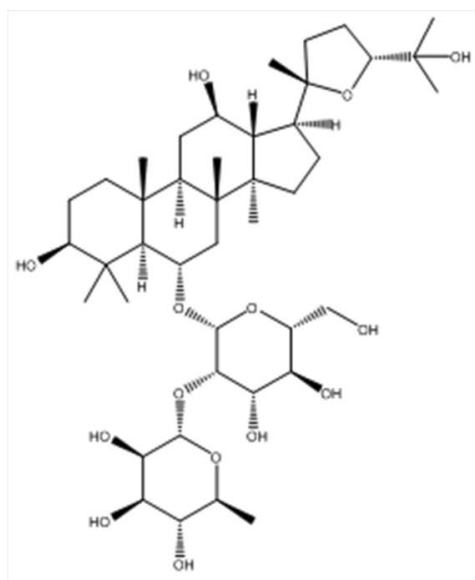

Pseudoginsenoside-F11 (14)

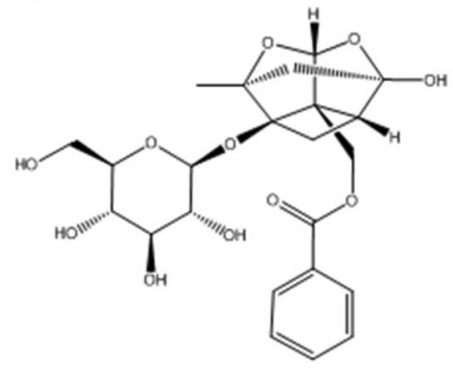

Paeoniflorin (17)

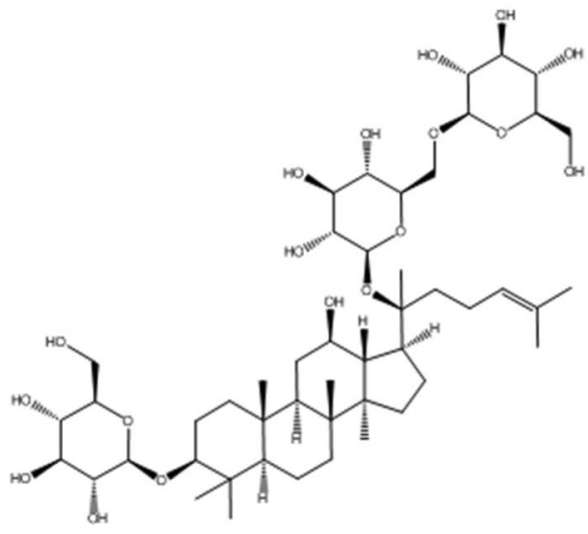

Gypenoside XVII (15)<smiles></smiles>

Hinokitiol (16)<smiles>CC(C)=CCC/C(C)=C/C[C@H]1C[C@@]2(CC=C(C)C)C(O)=C(C(=O)c3ccc(O)c(O)c3)C(=O)[C@@]3(C[C@@]23CC=C(C)C)C1=O</smiles>

Oblongifolin C (18)

Fig. 6 Chemical structures of terpenoids, including pseudoginsenoside-F11, gypenoside XVII, hinokitiol, paeoniflorin, and oblongifolin C

\section{Steroids}

\section{Ouabain}

Ouabain (19, Fig. 7), a cardiac glycoside, is an mTOR and $\mathrm{Na}^{+} / \mathrm{K}^{+}$-ATPase inhibitor. It activates TFEB, induces downstream autophagy-lysosomal gene expression, protects against okadaic acid (OA)-induced neuronal damage, reduces $\mathrm{p}$-Tau aggregates, improves the rough-eye phenotype of tau transgenic flies, and restores memory performance in Tau-P301L mice [69].

\section{Cardiac glycoside-ingenol derivative Hep 14}

Cardiac glycoside-ingenol derivative Hep14 (20, Fig. 7), derived from Euphorbia peplus Linn, activates TFEB through the PKC-GSK3 cascade. In addition, PKC activation further activates JNK2 and p38, which in turn phosphorylate ZKSCAN3. ZKSCAN3 translocates to the cytoplasm, consequently ameliorating transcriptional repression. Thus, HEP14, which controls two protein phosphorylation cascades by PKC to activate lysosomal gene expression, obviously promotes lysosome-dependent clearance of lipid droplets and aggregated proteins in cell models and reduces amyloid $\beta$ plaques in APP/PS1 mice [70].

\section{Digoxin}

Digoxin (21, Fig. 7) is a natural cardiac glycoside. It has been recently reported that digoxin inhibits $\mathrm{Na}^{+} / \mathrm{K}^{+}$ATPase, increases the cytosolic $\mathrm{Ca}^{2+}$ level, and leads to TFEB dephosphorylation and activation. TFEB activation induced by digoxin engages lipid catabolism and ameliorates metabolic syndromes [71].

\section{Disaccharides}

\section{Trehalose}

Trehalose (22, Fig. 8), a disaccharide composed of two glucose molecules, can be synthesized by many fungi and plants. Activation of TFEB by trehalose in an mTORindependent manner enhances autophagy and the clearance of TDP-43 aggregates, which are related to ALS diseases [38]. Trehalose has been demonstrated to induce TFEB nuclear translocation and upregulate TFEB target genes. TFEB silencing offsets the degradation of misfolded protein in ALS and SBMA motoneuron diseases. Notably, melibiose and lactulose exert similar effects [72]. Trehalose activates TFEB via Akt inhibition and enhances cellular clearance to reduce neuropathology in Batten disease [73]. Trehalose induces TFEB, driving the 

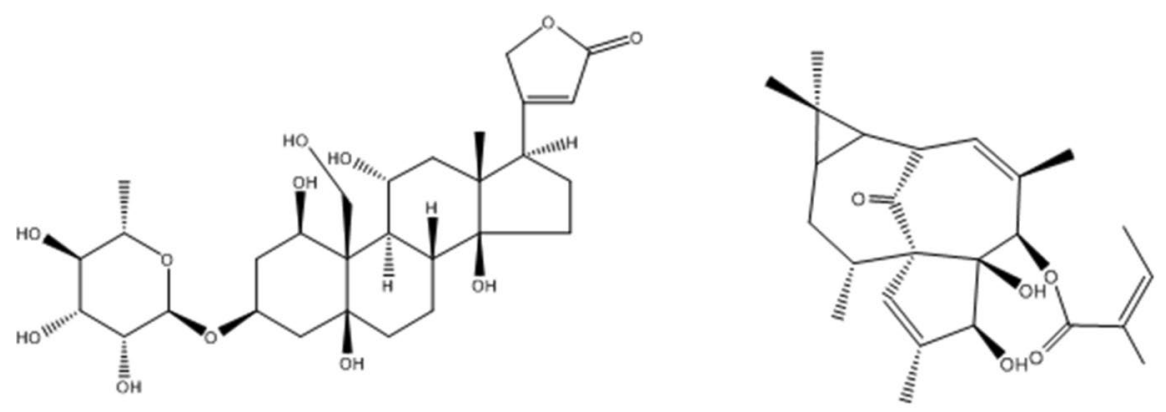

Ouabain (19) Cardiac glycoside-ingenol derivative Hep14 (20)

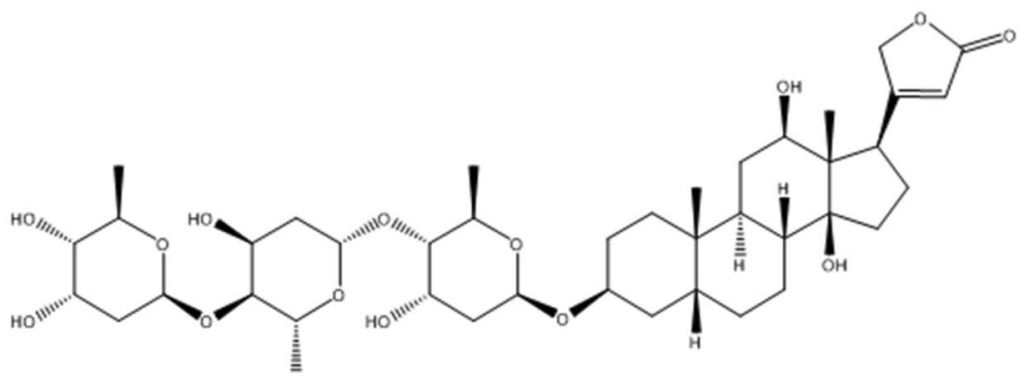

Digoxin (21)

Fig. 7 Chemical structures of steroids, including ouabain, cardiac glycoside-ingenol derivative Hep14, and digoxin<smiles>C[C@@H]1[C@@H](CO)O[C@H](C[C@H]2O[C@H](CO)[C@@H](O)[C@H](O)[C@H]2O)[C@H](O)[C@@H]1O</smiles>

Trehalose (22)<smiles>O=C(O)/C=C/c1ccccc1</smiles>

Cinnamic acid (23)

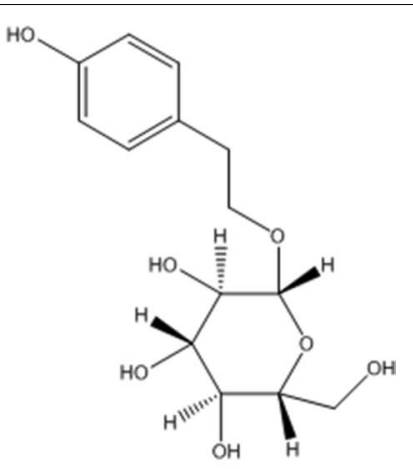

Salidroside (24)

Fig. 8 The chemical structures of trehalose, cinnamic acid, and salidroside

macrophage autophagy-lysosome system to reduce atherosclerotic plaque burden [90].

\section{Others}

\section{Cinnamic acid}

Cinnamic acid (23, Fig. 8), an aromatic carboxylic acid, is abundant in vegetables, fruits, and grains. It has been demonstrated that cinnamic acid activates PGC- $1 \alpha$ to upregulate TFEB and it induces lysosomal biogenesis in primary brain cells. Moreover, cinnamic acid treatment can reduce the amyloid plaque burden and improve the memory and behavioral performance of $5 \times$ XAD mice in a PGC-1 $\alpha$-dependent manner [74].

\section{Salidroside}

Salidroside (24, Fig. 8), a phenylpropanoid glycoside isolated from the plant Rhodiola rosea L., has been proven to possess anti-inflammatory, anti-oxidant, and anticancer 
properties [91-93]. Salidroside activates TFEB nuclear translocation and increases TFEB reporter activity, which contributes to lysosomal biogenesis and the expression of autophagy-related genes. Salidroside promotes apoptosis and induces autophagy by targeting the ROS-TFEB signaling pathway in human chondrosarcoma cells. Additionally, inhibition of autophagy may improve the antitumor activity of salidroside [75].

\section{Discussion}

ALP, as a vital cellular degradative machinery, is involved in a variety of human diseases. TFEB, coordinating autophagy induction with lysosomal biogenesis, makes it an attractive therapeutic target. Thus far, it has been reported that some nonnatural products can activate TFEB, including rapamycin, fubendazole [94], alexidine dihydrochloride [71], ezetimibe [95], gemfibrozil [96], aspirin [97] and so on. Compared with nonnatural products, natural products have played a significant role in health maintenance and disease control due to their properties of fewer side effects and multitargeted activity. In addition, natural products have been used as lead compounds for structural modification to synthesize derivatives, such as LY294002, a commonly used kinase inhibitor [98]. However, currently known TFEB activators from natural products are partial mTOR inhibitors. The mTOR kinase participates in the regulation of cell growth and metabolism, and thus mTOR inhibitors are likely to elicit undesirable side effects leading to limitations of their long-term use [99].

TFEB overexpression is related to the progression of cancers. At the same time, inefficient activation of TFEB may not only lead to ineffective treatment but also aggravate disease [2]. How to balance the beneficial and harmful effects of autophagy? Given the complexity of the ALP machinery, TFEB activation needs to be tightly regulated. Some compounds are autophagy inducers or inhibitors at specific time points. Whether these autophagy inducers or inhibitors have the opposite effect at other time points? For example, fangchinoline promotes the nuclear translocation of TFEB and expression of its target genes at an early stage of autophagy. But in the late period of treatment, fangchinoline inhibits the fusion of the autophagosome and lysosome, and affects lysosomal function, leading to a decrease in the autophagic flux [64]. Accordingly, it is necessary to screen autophagy inducers or inhibitors by using a real-time monitored method. In addition, the concentration to effectively activate TFEB may be relatively higher than the reported blood concentration seen in human clinical experiments, such as quercetin. The dose and duration will have to be further discussed for the treatment of human diseases.
Although there have been no TFEB activators used in the clinic so far, some drugs already in use have effects on TFEB activation. Whether their pharmacological effects are partly related to TFEB activation is worthy of further study. Taken together, caution should be applied during the use of TFEB activators for disease treatment.

\section{Conclusions}

TFEB is an attractive target due to its engagement in multiple human diseases associated with ALP dysfunction. TCM-derived natural products have been valued as important sources for drug discovery because of their well-documented therapeutic efficacies. Although some natural products have been reported to activate TFEB and ameliorate phenotypes, their molecular properties, the complex machinery, and the lack of clinical experimental evidence limits their further development. Furthermore, the discovery of clinically available TFEB activators may be a promising strategy for the treatment of diseases associated with ALP dysfunction.

\section{Abbreviations}

ALP: Autophagy-lysosome pathway ; TFEB: Transcription factor EB; TCM:Traditional Chinese medicine; UPS: ubiquitin-proteasome system; CMA: Chaperone-mediated autophagy; PI3K: Class III phosphatidylinositol 3-kinase; CLEAR: Coordinated lysosomal expression and regulation; mTOR: Mammalian (or Mechanistic) target of rapamycin; mTORC: mTOR complex; Raptor: Regulatory associated protein of mTOR; GßL: G protein $\beta$-subunit-like protein; PRAS40: Proline-rich Akt substrate of 40 kDa; DEPTOR: DEP domain-containing mTORinteracting protein; AMPK: AMP-activated protein kinase; Rictor: Rapamycininsensitive companion of mTOR; SIN: Stress-activated protein kinase-interacting protein; PROTOR: Protein observed with Rictor; ERK2/MAPK1: Extracellular signal-regulated kinase 2; MCOLN1: Calcium channel mucolipin 1; PGC-1a/ PPARGC1A: Peroxisome proliferator activated receptor- $\gamma$ coactivator 1a; LSDs: Lysosomal storage disorders; GAA: Acid alpha-glucosidase; GC: Glucocerebrosidase; MSD: Multiple sulfatase deficiency; GAGs: Glysosaminoglycans; MPS: Mucopolysaccharidosis; HD: Huntington's disease; HTT: Huntingtin; polyQ: Polyglutamine; PD: Parkinson's disease; AD: Alzheimer's disease; A $3:$ $\beta$-Amyloid peptides; NFTs: Neurofibrillary tangles; APP: Amyloid precursor protein; PS: Presenilin; SBMA: Spinal and bulbar muscular atrophy; AR: Androgen receptor; ALS: Amyotrophic lateral sclerosis; TDP-43: Transactive response (TAR) DNAbinding protein 43 kDa; GSK3: Glycogen synthase kinase-3; ROS: Reactive oxygen species; MAO: Monoamine oxidase; H2O2: Hydrogen peroxide; HUVECs: Human umbilical vein endothelial cells; MEFs: Mouse embryonic fibroblasts; CTF- $\beta /$ a: APP C-terminal fragments; 6-OHDA/AA: 6-Hydroxydopamine/ ascorbic acid; MPTP: 1-methyl-4-phenyl-1,2,3,6-tetrahydropyridine; NSCLC: Nonsmall cell lung cancer; NF-YA: Nuclear factor-YA; STX17: SNARE protein syntaxin 17; OA: Okadaic acid.

\section{Acknowledgements}

Not applicable.

\section{Authors' contributions}

ZJZ conceived and organized the review. JX drafted the manuscript. ZJZ and $X Q Z$ revised the manuscript. All authors read and approved the final manuscript.

\section{Funding}

This research is funded by the National Key R\&D Program of China (No. 2017YFC1703802), the National Natural Science Foundation of China (Nos. U1801287, 81872842, 82073821), the Natural Science Foundation of Guangdong Province (2020A1515011061), the Science and Technology Planning Project of Guangdong Province (Nos. 2020B1111110004 and 2018B020207008), 
and the Local Innovative and Research Teams Project of Guangdong Pearl River Talents Program (No. 2017BT01 Y036).

\section{Availability of data and materials}

Data sharing is not applicable to this article as no datasets were generated or analyzed during the current study.

\section{Ethics approval and consent to participate}

Not applicable.

\section{Consent for publication}

Not applicable.

\section{Competing interests}

The authors declare that they have no competing interests.

Received: 5 July 2020 Accepted: 6 November 2020

Published online: 23 November 2020

\section{References}

1. Wang SF, Wu MY, Cai CZ, Li M, Lu JH. Autophagy modulators from traditional Chinese medicine: Mechanisms and therapeutic potentials for cancer and neurodegenerative diseases. J Ethnopharmacol. 2016:194:861-76.

2. Martini-Stoica H, XuY, Ballabio A, Zheng H. The Autophagy-Lysosomal Pathway in Neurodegeneration: A TFEB Perspective. Trends neurosci. 2016;39(4):221-34.

3. Jung CH, Jun CB, Ro S-H, Kim Y-M, Otto NM, Cao J, Kundu M, Kim D-H. ULK-Atg13-FIP200 complexes mediate mTOR signaling to the autophagy machinery. Mol Biol Cell. 2009;20(7):1992-2003.

4. Fan W, Nassiri A, Zhong Q. Autophagosome targeting and membrane curvature sensing by Barkor/Atg 14(L). Proc Natl Acad Sci USA. 2011;108(19):7769-74

5. Pattingre S, Tassa A, Qu X, Garuti R, Liang XH, Mizushima N, Packer M, Schneider MD, Levine B. BCl-2 Antiapoptotic Proteins Inhibit Beclin 1-Dependent Autophagy. Cell. 2005;122(6):927-39.

6. Satoo K, Noda NN, Kumeta H, Fujioka Y, Mizushima N, Ohsumi Y, Inagaki F. The structure of Atg4B-LC3 complex reveals the mechanism of LC3 processing and delipidation during autophagy. EMBO J. 2009;28(9):1341-50.

7. Palmieri M, Impey S, Kang H, di Ronza A, Pelz C, Sardiello M, Ballabio A. Characterization of the CLEAR network reveals an integrated control of cellular clearance pathways. Hum Mol Genet. 2011;20(19):3852-66.

8. Decressac M, Mattsson B, Weikop P, Lundblad M, Jakobsson J, Bjorklund A. TFEB-mediated autophagy rescues midbrain dopamine neurons from alpha-synuclein toxicity. Proc Natl Acad Sci USA. 2013;110(19):E1817-26.

9. Xiao Q, Yan P, Ma X, Liu H, Perez R, Zhu A, Gonzales E, Tripoli DL, Czerniewski L, Ballabio A, Cirrito JR, Diwan A, Lee J-M. Neuronal-Targeted TFEB Accelerates Lysosomal Degradation of APP, Reducing A $B$ Generation and Amyloid Plaque Pathogenesis. J Neurosci. 2015;35(35):12137-51.

10. Jewell JL, Russell RC, Guan K-L. Amino acid signalling upstream of mTOR. Nat Rev Mol Cell Biol. 2013;14(3):133-9.

11. Lamming DW, Ye L, Katajisto P, Goncalves MD, Saitoh M, Stevens DM, Davis JG, Salmon AB, Richardson A, Ahima RS, Guertin DA, Sabatini DM, Baur JA. Rapamycin-induced insulin resistance is mediated by mTORC2 loss and uncoupled from longevity. Science. 2012;335(6076):1638-43.

12. Mammucari C, Milan G, Romanello V, Masiero E, Rudolf R, Del Piccolo P, Burden SJ, Di Lisi R, Sandri C, Zhao J, Goldberg AL, Schiaffino S, Sandri M. FoxO3 Controls Autophagy in Skeletal Muscle In Vivo. Cell Metab. 2007:6(6):458-71.

13. Martina JA, Diab HI, Li H, Puertollano R. Novel roles for the MiTF/TFE family of transcription factors in organelle biogenesis, nutrient sensing, and energy homeostasis. Cell Mol Life Sci. 2014;71(13):2483-97.

14. Napolitano G, Ballabio A. TFEB at a glance. J Cell Sci. 2016;129(13):2475-81.

15. Sardiello M, Palmieri M, di Ronza A, Medina DL, Valenza M, Gennarino VA, Di Malta C, Donaudy F, Embrione V, Polishchuk RS, Banfi S, Parenti G, Cattaneo E, Ballabio A. A Gene Network Regulating Lysosomal Biogenesis and Function. Science. 2009;325(5939):473.
16. Settembre C, Di Malta C, Polito VA, Garcia Arencibia M, Vetrini F, Erdin S, Erdin SU, Huynh T, Medina D, Colella P, Sardiello M, Rubinsztein DC, Ballabio A. TFEB links autophagy to lysosomal biogenesis. Science. 2011;332(6036):1429-33.

17. Seok S, Fu T, Choi S-E, Li Y, Zhu R, Kumar S, Sun X, Yoon G, Kang Y, Zhong W, Ma J, Kemper B, Kemper JK. Transcriptional regulation of autophagy by an FXR-CREB axis. Nature. 2014;516(7529):108-11.

18. Evans T, Zhang X, Jeong S-J, He A, Song E, Bhattacharya S, Holloway K, Lodhi I, Razani B. TFEB drives PGC-1 a expression in adipocytes to protect against diet-induced metabolic dysfunction. Sci Signal. 2019;12:eaau2281.

19. Kim YS, Lee H-M, Kim JK, Yang C-S, Kim TS, Jung M, Jin HS, Kim S, Jang J, Oh GT, Kim J-M, Jo E-K. PPAR-a Activation Mediates Innate Host Defense through Induction of TFEB and Lipid Catabolism. J Immunol. 2017;198(8):3283.

20. Ghosh A, Jana M, Modi K, Gonzalez F, Sims K, Berry-Kravis E, Pahan K. Activation of peroxisome proliferator-activated receptor a induces lysosomal biogenesis in brain cells implications for lysosomal storage disorders. J Biol Chem. 2015;290(16):10309-24.

21. Medina DL, Di Paola S, Peluso I, Armani A, De Stefani D, Venditti R, Montefusco S, Scotto-Rosato A, Prezioso C, Forrester A, Settembre C, Wang W, Gao Q, Xu H, Sandri M, Rizzuto R, De Matteis MA, Ballabio A. Lysosomal calcium signalling regulates autophagy through calcineurin and TFEB. Nat Cell Biol. 2015;17(3):288-99.

22. Settembre C, Zoncu R, Medina DL, Vetrini F, Erdin S, Erdin S, Huynh T, Ferron M, Karsenty G, Vellard MC, Facchinetti V, Sabatini DM, Ballabio A. A lysosome-to-nucleus signalling mechanism senses and regulates the lysosome via mTOR and TFEB. EMBO J. 2012;31(5):1095-108.

23. Roczniak-Ferguson A, Petit CS, Froehlich F, Qian S, Ky J, Angarola B, Walther TC, Ferguson SM. The transcription factor TFEB links mTORC1 signaling to transcriptional control of lysosome homeostasis. Sci Signal. 2012;5(228):ra42.

24. Martina JA, Diab HI, Brady OA, Puertollano R. TFEB and TFE3 are novel components of the integrated stress response. EMBO J. 2016;35(5):479-95.

25. Parenti G, Andria G, Ballabio A. Lysosomal storage diseases: from pathophysiology to therapy. Annual review of medicine. 2015;66:471-86.

26. Spampanato C, Feeney E, Li L, Cardone M, Lim JA, Annunziata F, Zare H, Polishchuk R, Puertollano R, Parenti G, Ballabio A, Raben N. Transcription factor EB (TFEB) is a new therapeutic target for Pompe disease. EMBO Mol Med. 2013;5(5):691-706.

27. Song W, Wang F, Savini M, Ake A, di Ronza A, Sardiello M, Segatori L. TFEB regulates lysosomal proteostasis. Hum Mol Genet. 2013;22(10):1994-2009.

28. Medina DL, Fraldi A, Bouche V, Annunziata F, Mansueto G, Spampanato C, Puri C, Pignata A, Martina JA, Sardiello M, Palmieri M, Polishchuk R, Puertollano R, Ballabio A. Transcriptional activation of lysosomal exocytosis promotes cellular clearance. Dev Cell. 2011;21(3):421-30.

29. Rega LR, Polishchuk E, Montefusco S, Napolitano G, Tozzi G, Zhang J, Bellomo F, Taranta A, Pastore A, Polishchuk R, Piemonte F, Medina DL, Catz SD, Ballabio A, Emma F. Activation of the transcription factor EB rescues lysosomal abnormalities in cystinotic kidney cells. Kidney Int. 2016;89(4):862-73.

30. Tsunemi T, Ashe TD, Morrison BE, Soriano KR, Au J, Roque RA, Lazarowski ER, Damian VA, Masliah E, La Spada AR. PGC-1alpha rescues Huntington's disease proteotoxicity by preventing oxidative stress and promoting TFEB function. Sci Transl Med. 2012:4(142):142ra97.

31. Wang ZY, Liu JY, Yang CB, Malampati S, Huang YY, Li MX, Li M, Song JX. Neuroprotective Natural Products for the Treatment of Parkinson's Disease by Targeting the Autophagy-Lysosome Pathway: A Systematic Review. Phytother Res. 2017;31(8):1119-27.

32. Dehay B, Bové J, Rodríguez-Muela N, Perier C, Recasens A, Boya P, Vila M. Pathogenic lysosomal depletion in Parkinson's disease. J Neurosci. 2010;30(37):12535-44.

33. Nezich CL, Wang C, Fogel Al, Youle RJ. MiT/TFE transcription factors are activated during mitophagy downstream of Parkin and Atg5. J Cell Biol. 2015;210(3):435-50

34. Siddiqui A, Bhaumik D, Chinta SJ, Rane A, Rajagopalan S, Lieu CA, Lithgow GJ, Andersen JK. Mitochondrial Quality Control via the PGC1alpha-TFEB Signaling Pathway Is Compromised by Parkin Q311X Mutation But Independently Restored by Rapamycin. J Neurosci. 2015;35(37):12833-44. 
35. Malampati S, Song JX, Chun-Kit Tong B, Nalluri A, Yang CB, Wang Z, Gopalkrishnashetty Sreenivasmurthy S, Zhu Z, Liu J, Su C, Krishnamoorthi S, lyaswamy A, Cheung KH, Lu JH, Li AM. Targeting Aggrephagy for the Treatment of Alzheimer's Disease. Cells. 2020;9:2.

36. Polito VA, Li H, Martini-Stoica H, Wang B, Yang L, Xu Y, Swartzlander DB, Palmieri M, di Ronza A, Lee VMY, Sardiello M, Ballabio A, Zheng H. Selective clearance of aberrant tau proteins and rescue of neurotoxicity by transcription factor EB. EMBO Mol Med. 2014;6(9):1142-60.

37. Tohnai $G$, Adachi $H$, Katsuno M, Doi H, Matsumoto S, Kondo N, Miyazaki Y, lida M, Nakatsuji H, Qiang Q, Ding Y, Watanabe H, Yamamoto M, Ohtsuka K, Sobue G. Paeoniflorin eliminates a mutant AR via NF-YA-dependent proteolysis in spinal and bulbar muscular atrophy. Hum Mol Genet. 2014;23(13):3552-65.

38. Wang Y, Liu FT, Wang YX, Guan RY, Chen C, Li DK, Bu L, Song J, Yang Y, Dong $Y$, Chen $Y$, Wang J. Autophagic modulation by trehalose reduces accumulation of TDP-43 in a cell model of amyotrophic lateral sclerosis via TFEB activation. Neurotox Res. 2018;34:1.

39. Sohn EJ, Park HT. Natural agents mediated autophagic signal networks in cancer. Cancer Cell Int. 2017;17:110.

40. Cuomo F, Altucci L, Cobellis G. Autophagy Function and Dysfunction: Potential Drugs as Anti-Cancer Therapy. Cancers. 2019;11:10.

41. Marchand B, Arsenault D, Raymond-Fleury A, Boisvert FM, Boucher MJ. Glycogen synthase kinase-3 (GSK3) inhibition induces prosurvival autophagic signals in human pancreatic cancer cells. J Biol Che. 2015;290(9):5592-605.

42. Kauffman EC, Ricketts CJ, Rais-Bahrami S, Yang Y, Merino MJ, Bottaro DP, Srinivasan R, Linehan WM. Molecular genetics and cellular features of TFE3 and TFEB fusion kidney cancers. Nat Rev Urol. 2014;11 (8):465-75.

43. Kundu ST, Grzeskowiak CL, Fradette JJ, Gibson LA, Rodriguez LB, Creighton CJ, Scott KL, Gibbons DL. TMEM106B drives lung cancer metastasis by inducing TFEB-dependent lysosome synthesis and secretion of cathepsins. Nat Commun. 2018;9(1):2731.

44. Settembre C, De Cegli R, Mansueto G, Saha PK, Vetrini F, Visvikis O, Huynh T, Carissimo A, Palmer D, Klisch TJ, Wollenberg AC, Di Bernardo D, Chan L, Irazoqui JE, Ballabio A. TFEB controls cellular lipid metabolism through a starvation-induced autoregulatory loop. Nat Cell Biol. 2013;15(6):647-58.

45. Manni ME, Rigacci S, Borchi E, Bargelli V, Miceli C, Giordano C, Raimondi L, Nediani C. Monoamine Oxidase Is Overactivated in Left and Right Ventricles from Ischemic Hearts: An Intriguing Therapeutic Target. Oxid Med Cell Longev. 2016;2016:4375418.

46. Terman A, KurzT, Navratil M, Arriaga EA, Brunk UT. Mitochondrial turnover and aging of long-lived postmitotic cells: the mitochondrial-lysosomal axis theory of aging. Antioxid Redox Signal. 2010;12(4):503-35.

47. Santin $Y$, Sicard $P$, Vigneron F, Guilbeau-Frugier $C$, Dutaur M, Lairez $O$, Couderc B, Manni D, Korolchuk V, Lezoualch F, Parini A, Mialet-Perez J. Oxidative stress by monoamine oxidase-A impairs transcription factor EB activation and autophagosome clearance, leading to cardiomyocyte necrosis and heart failure. Antioxid Redox Signal. 2016;25:10.

48. Miceli C, Santin Y, Manzella N, Coppini R, Berti A, Stefani M, Parini A, Mialet-Perez J, Nediani C. Oleuropein Aglycone Protects against MAOA-Induced Autophagy Impairment and Cardiomyocyte Death through Activation of TFEB. Oxid Med Cell Longev. 2018;2018:8067592.

49. Zhou X, Yang J, Zhou M, Zhang Y, Liu Y, Hou P, Zeng X, Yi L, Mi M. Resveratrol attenuates endothelial oxidative injury by inducing autophagy via the activation of transcription factor EB. Nutr Metab. 2019;16:42.

50. Pastore N, Blomenkamp K, Annunziata F, Piccolo P, Mithbaokar P, Maria Sepe R, Vetrini F, Palmer D, Ng P, Polishchuk E, lacobacci S, Polishchuk R, Teckman J, Ballabio A, Brunetti-Pierri N. Gene transfer of master autophagy regulator TFEB results in clearance of toxic protein and correction of hepatic disease in alpha-1-anti-trypsin deficiency. EMBO Mol Med. 2013;5(3):397-412.

51. Samie M, Cresswell P. The transcription factor TFEB acts as a molecular switch that regulates exogenous antigen-presentation pathways. Nat Immunol. 2015;16(7):729-36.

52. Pastore N, Brady OA, Diab HI, Martina JA, Sun L, Huynh T, Lim J-A, Zare $H$, Raben N, Ballabio A, Puertollano R. TFEB and TFE3 cooperate in the regulation of the innate immune response in activated macrophages. Autophagy. 2016;12(8):1240-58.

53. Ferron M, Settembre C, Shimazu J, Lacombe J, Kato S, Rawlings DJ, Ballabio A, Karsenty G. A RANKL-PKCbeta-TFEB signaling cascade is necessary for lysosomal biogenesis in osteoclasts. Genes Dev. 2013;27(8):955-69.
54. Zhang J, Wang J, Xu J, Lu Y, Jiang J, Wang L, Shen H-M, Xia D. Curcumin targets the TFEB-lysosome pathway for induction of autophagy. Oncotarget. 2016;7(46):75659-71.

55. Song JX, Malampati S, Zeng Y, Durairajan SSK, Yang CB, Tong BC, lyaswamy A, Shang WB, Sreenivasmurthy SG, Zhu Z, Cheung KH, Lu JH, Tang C, Xu N, Li M. A small molecule transcription factor EB activator ameliorates beta-amyloid precursor protein and Tau pathology in Alzheimer's disease models. Aging cell. 2020;19(2):e13069.

56. Zhuang XX, Wang SF, Tan Y, Song JX, Zhu Z, Wang ZY, Wu MY, Cai CZ, Huang ZJ, Tan JQ, Su HX, Li M, Lu JH. Pharmacological enhancement of TFEB-mediated autophagy alleviated neuronal death in oxidative stressinduced Parkinson's disease models. Cell Death Dis. 2020;1 1(2):128.

57. Wang Z, Yang C, Liu J, Chun-Kit Tong B, Zhu Z, Malampati S, Gopalkrishnashetty Sreenivasmurthy S, Cheung KH, lyaswamy A, Su C, Lu J, Song J, Li M. A Curcumin Derivative Activates TFEB and Protects Against Parkinsonian Neurotoxicity in Vitro. Int J Mol Sci. 2020;21:4.

58. Gao L, Li X, Meng S, Ma T, Wan L, Xu S. Chlorogenic Acid Alleviates Abeta25-35-Induced Autophagy and Cognitive Impairment via the mTOR/TFEB Signaling Pathway. Drug Des Dev Ther. 2020;14:1705-16.

59. Moskot M, Montefusco S, Jakobkiewicz-Banecka J, Mozolewski P, Wegrzyn A, Di Bernardo D, Wegrzyn G, Medina DL, Ballabio A, Gabig-Ciminska M. The phytoestrogen genistein modulates lysosomal metabolism and transcription factor EB (TFEB) activation. J Biol Chem. 2014;289(24):17054-69.

60. Moskot M, Jakobkiewicz-Banecka J, Kloska A, Smolinska E, Mozolewski P, Malinowska M, Rychlowski M, Banecki B, Wegrzyn G, Gabig-Ciminska M. Modulation of expression of genes involved in glycosaminoglycan metabolism and lysosome biogenesis by flavonoids. Sci Rep. 2015;5:9378.

61. Huang Y, Chen Y, Shaw AM, Goldfine H, Tian J, Cai J. Enhancing TFEBMediated Cellular Degradation Pathways by the MTORC1 Inhibitor Quercetin. Oxid Med Cell Longev. 2018;2018:5073420.

62. Kim S, Choi KJ, Cho SJ, Yun SM, Jeon JP, Koh YH, Song J, Johnson GVW, Jo C. Fisetin stimulates autophagic degradation of phosphorylated tau via the activation of TFEB and Nrf2 transcription factors. Sci Rep. 2016;6:24933

63. Durairajan SSK, Huang Y, Chen L, Song J, Liu L, Li M. Corynoxine isomers decrease levels of amyloid- $\beta$ peptide and amyloid- $\beta$ precursor protein by promoting autophagy and lysosome biogenesis. Molecular Neurodegeneration. 2013;8(1):P16.

64. Tang ZH, Guo X, Cao WX, Chen X, Lu JJ. Fangchinoline accumulates autophagosomes by inhibiting autophagic degradation and promoting TFEB nuclear translocation. RSC Adv. 2017;7(67):42597-605.

65. Yao XC, Xue X, Zhang HT, Zhu MM, Yang XW, Wu CF, Yang JY. Pseudoginsenoside-F11 alleviates oligomeric $\beta$-amyloid-induced endosome-lysosome defects in microglia. Traffic. 2019;20(1):61-70.

66. Meng X, Luo Y, Liang T, Wang M, Zhao J, Sun G, Sun X. Gypenoside XVII Enhances Lysosome Biogenesis and Autophagy Flux and Accelerates Autophagic Clearance of Amyloid- $\beta$ through TFEB Activation. J Alzheimer's Dis. 2016;52(3):1135-50.

67. Lee TB, Jun JH. Can Hinokitiol Kill Cancer Cells? Alternative Therapeutic Anticancer Agent via Autophagy and Apoptosis. Korean J Clin Lab Sci. 2019;51(2):221-34.

68. Wu M, Lao YZ, Tan HS, Lu G, Ren Y, Zheng ZQ, Yi J, Fu WW, Shen HM, Xu HX. Oblongifolin C suppresses lysosomal function independently of TFEB nuclear translocation. Acta Pharmacol Sin. 2019;40(7):929-37.

69. Song HL, Demirev AV, Kim NY, Kim DH, Yoon SY. Ouabain activates transcription factor $E B$ and exerts neuroprotection in models of Alzheimer's disease. Mol Cell Neurosci. 2019;95:13-24.

70. Li Y, Xu M, Ding X, Yan C, Song Z, Chen L, Huang X, Wang X, Jian Y, Tang G, Tang C, Di Y, Mu S, Liu X, Liu K, Li T, Wang Y, Miao L, Guo W, Hao X, Yang C. Protein kinase $C$ controls lysosome biogenesis independently of mTORC1. Nat Cell Biol. 2016;18(10):1065-77.

71. Wang C, Niederstrasser H, Douglas PM, Lin R, Jaramillo J, Li Y, Oswald NW, Zhou A, McMillan EA, Mendiratta S, Wang Z, Zhao T, Lin Z, Luo M, Huang G, Brekken RA, Posner BA, MacMillan JB, Gao J, White MA. Small-molecule TFEB pathway agonists that ameliorate metabolic syndrome in mice and extend C. elegans lifespan. Nat Commun. 2017:8(1):2270.

72. Rusmini P, Cortese K, Crippa V, Cristofani R, Cicardi ME, Ferrari V, Vezzoli G, Tedesco B, Meroni M, Messi E, Piccolella M, Galbiati M, Garrè M, Morelli E, Vaccari T, Poletti A. Trehalose induces autophagy via lysosomal-mediated TFEB activation in models of motoneuron degeneration. Autophagy. 2019;15(4):631-51. 
73. Palmieri M, Pal R, Nelvagal HR, Lotfi P, Stinnett GR, Seymour ML, Chaudhury A, Bajaj L, Bondar W, Bremner L, Saleem U, Tse DY, Sanagasetti D, Wu SM, Neilson JR, Pereira FA, Pautler RG, Rodney GG, Cooper JD, Sardiello M. mTORC1-independent TFEB activation via Akt inhibition promotes cellular clearance in neurodegenerative storage diseases. Nat Commun. 2017;8:14338.

74. Chandra S, Roy A, Jana M, Pahan K. Cinnamic acid activates PPARa to stimulate Lysosomal biogenesis and lower Amyloid plaque pathology in an Alzheimer's disease mouse model. Neurobiol Dis. 2019:124:379-95.

75. Zeng W, Xiao T, Cai A, Cai W, Liu H, Liu J, Li J, Tan M, Xie L, Liu Y, Yang X, Long Y. Inhibiting ROS-TFEB-Dependent Autophagy Enhances Salidroside-Induced Apoptosis in Human Chondrosarcoma Cells. Cell physiol Biochem. 2017:43(4):1487-502.

76. Zheng K, Dai X, Xiao N, Wu X, Wei Z, Fang W, Zhu Y, Zhang J, Chen X. Curcumin Ameliorates Memory Decline via Inhibiting BACE1 Expression and beta-Amyloid Pathology in 5xFAD Transgenic Mice. Mol Neurobiol. 2017;54(3):1967-77.

77. Wang A, Wang J, Zhang S, Zhang H, Xu Z, Li X. Curcumin inhibits the development of non-small cell lung cancer by inhibiting autophagy and apoptosis. Exp Ther Med. 2017:14(5):5075-80.

78. Avila-Rojas SH, Lira-Leon A, Aparicio-Trejo OE, Reyes-Fermin LM, PedrazaChaverri J. Role of Autophagy on Heavy Metal-Induced Renal Damage and the Protective Effects of Curcumin in Autophagy and Kidney Preservation. Medicina. 2019;55:7.

79. Song JX, Sun YR, Peluso I, Zeng Y, Yu X, Lu JH, Xu Z, Wang MZ, Liu LF, Huang YY, Chen LL, Durairajan SSK, Zhang HJ, Zhou B, Zhang HQ, Lu A, Ballabio A, Medina DL, Guo Z, Li M. A novel curcumin analog binds to and activates TFEB in vitro and in vivo independent of MTOR inhibition. Autophagy. 2016;12(8):1372-89.

80. Magini A, Polchi A, Di Meo D, Buratta S, Chiaradia E, Germani R, Emiliani C, Tancini B. Curcumin Analogue C1 Promotes Hex and Gal Recruitment to the Plasma Membrane via mTORC1-Independent TFEB Activation. Int J Mol Sci. 2019;20:6

81. Bao J, Zheng L, Zhang Q, Li X, Zhang X, Li Z, Bai X, Zhang Z, Huo W, Zhao $X$, Shang S, Wang Q, Zhang C, Ji J. Deacetylation of TFEB promotes fibrillar $A \beta$ degradation by upregulating lysosomal biogenesis in microglia. Protein Cell. 2016;7(6):417-33.

82. Huang J, Wang X, Zhu Y, Li Z, Zhu YT, Wu JC, Qin ZH, Xiang M, Lin F. Exercise activates lysosomal function in the brain through AMPK-SIRT1-TFEB pathway. CNS Neurosci Ther. 2019;25(6):796-807.

83. Rigacci S, Miceli C, Nediani C, Berti A, Cascella R, Pantano D, Nardiello P, Luccarini I, Casamenti F, Stefani M. Oleuropein aglycone induces autophagy via the AMPK/mTOR signalling pathway: a mechanistic insight. Oncotarget. 2015;6(34):35344-57.

84. Grossi C, Rigacci S, Ambrosini S, Ed Dami T, Luccarini I, Traini C, Failli P, Berti A, Casamenti F, Stefani M. The polyphenol oleuropein aglycone protects TgCRND8 mice against Aß plaque pathology. PLoS One. 2013;8(8):e71702.

85. Naveed M, Hejazi V, Abbas M, Kamboh AA, Khan GJ, Shumzaid M, Ahmad F, Babazadeh D, FangFang X, Modarresi-Ghazani F, WenHua L, XiaoHui Z. Chlorogenic acid (CGA): A pharmacological review and call for further research. Biomed Pharmacother. 2018;97:67-74.
86. Guo YP, Lin LG, Wang YT. Chemistry and pharmacology of the herb pair Flos Lonicerae japonicae-Forsythiae fructus. Chin Med. 2015;10:16.

87. Wang CM, Liu MY, Wang F, Wei MJ, Wang S, Wu CF, Yang JY. Anti-amnesic effect of pseudoginsenoside-F11 in two mouse models of Alzheimer's disease. Pharmacol Biochem Behav. 2013;106:57-67.

88. Zhang Z, Yang J, Liu C, Xie J, Qiu S, Yang X, Wu C. Pseudoginsenoside-F11 alleviates cognitive deficits and Alzheimer's disease-type pathologies in SAMP8 mice. Pharmacol Res. 2019;139:512-23.

89. Luo XQ, Li A, Yang $X$, Xiao X, Hu R, Wang TW, Dou XY, Yang DJ, Dong $Z$. Paeoniflorin exerts neuroprotective effects by modulating the M1/M2 subset polarization of microglia/macrophages in the hippocampal CA1 region of vascular dementia rats via cannabinoid receptor 2. Chin Med. 2018;13:14.

90. Evans TD, Jeong SJ, Zhang X, Sergin I, Razani B. TFEB and trehalose drive the macrophage autophagy-lysosome system to protect against atherosclerosis. Autophagy. 2018;14(4):724-6.

91. Zhao G, Shi A, Fan Z, Du Y. Salidroside inhibits the growth of human breast cancer in vitro and in vivo. Oncol Rep. 2015;33(5):2553-60.

92. Fan XJ, Wang Y, Wang L, Zhu M. Salidroside induces apoptosis and autophagy in human colorectal cancer cells through inhibition of PI3K Akt/mTOR pathway. Oncol Rep. 2016;36(6):3559-67.

93. Recio MC, Giner RM, Manez S. Immunmodulatory and Antiproliferative Properties of Rhodiola Species. Planta Med. 2016;82(11-12):952-60.

94. Chauhan S, Ahmed Z, Bradfute SB, Arko-Mensah J, Mandell MA, Won Cho S, Kimura T, Blanchet F, Waller A, Mudd MH, Jiang S, Sklar L, Timmins GS, Maphis N, Bhaskar K, Piguet V, Deretic V. Pharmaceutical screen identifies novel target processes for activation of autophagy with a broad translational potential. Nat Commun. 2015;6:8620.

95. Kim SH, Kim G, Han DH, Lee M, Kim I, Kim B, Kim KH, Song YM, Yoo JE, Wang HJ, Bae SH, Lee YH, Lee BW, Kang ES, Cha BS, Lee MS. Ezetimibe ameliorates steatohepatitis via AMP activated protein kinase-TFEBmediated activation of autophagy and NLRP3 inflammasome inhibition. Autophagy. 2017;13(10):1767-81.

96. Ghosh A, Jana M, Modi K, Gonzalez FJ, Sims KB, Berry-Kravis E, Pahan K. Activation of peroxisome proliferator-activated receptor alpha induces lysosomal biogenesis in brain cells: implications for lysosomal storage disorders. J Biol Chem. 2015;290(16):10309-24.

97. Chandra S, Jana M, Pahan K. Aspirin Induces Lysosomal Biogenesis and Attenuates Amyloid Plaque Pathology in a Mouse Model of Alzheimer's Disease via PPARalpha. J Neurosci. 2018;38(30):6682-99.

98. Walker EH, Pacold ME, Perisic O, Stephens L, Hawkins PT, Wymann MP, Williams RL. Structural Determinants of Phosphoinositide 3-Kinase Inhibition by Wortmannin, LY294002, Quercetin, Myricetin, and Staurosporine. Mol Cell. 2000;6(4):909-19.

99. Pallet $\mathrm{N}$, Legendre C. Adverse events associated with mTOR inhibitors. Expert Opin Drug Saf. 2013;12(2):177-86.

\section{Publisher's Note}

Springer Nature remains neutral with regard to jurisdictional claims in published maps and institutional affiliations.

\footnotetext{
Ready to submit your research? Choose BMC and benefit from:

- fast, convenient online submission

- thorough peer review by experienced researchers in your field

- rapid publication on acceptance

- support for research data, including large and complex data types

- gold Open Access which fosters wider collaboration and increased citations

- maximum visibility for your research: over 100M website views per year
}

At BMC, research is always in progress.

Learn more biomedcentral.com/submissions 